\title{
REAVALIAÇÃO E MELHORIA DOS PROCESSOS DE BENEFICIAMENTO DE NÃO TECIDOS COM BASE EM RECLAMAÇÕES DE CLIENTES
}

\section{REVALUETION AND IMPROVEMENT OF NONWONEN BENEFACTION PROCESS ON THE CUSTOMER CLAIN}

\author{
Luis Gustavo dos Santos Gomes \\ Tecnólogo em Gestão da Qualidade e Pós-graduando em Gestão Empresarial \\ Complexo de Ensino Superior de Cachoeirinha - CESUCA \\ Rua Monte Castelo 295, Bairro Marrocos, Gravataí-RS, CEP 94045-290 \\ Tel. (51) 99970235 e-mail: luisgustavo.gomes@gmail.com
}

\begin{abstract}
Resumo
Este estudo busca compreender os processos envolvidos na elaboração do produto e realizar melhorias de modo a satisfazer os clientes. A partir da análise de indicadores do sistema de gestão da qualidade, identificou-se os principais problemas que necessitam de ações corretivas/preventivas, entre esses, o número elevado de reclamações de clientes que adquirem produtos beneficiados. Neste trabalho, foi realizada a estratificação dessas reclamações por causas primárias e posteriormente identificadas as que necessitavam ser atacadas com prioridade. Foram aplicadas ferramentas gerenciais da qualidade para a melhoria do processo de beneficiamento de nãotecidos. Durante o desenvolvimento das ações, foi utilizado o ciclo de PDCA e realizado a execução de ações que visaram atender alguns itens da norma ISO 9001:2000. Com base em indicadores como o número de reclamações de clientes, o número de não-conformidades e auditorias da qualidade nos fornecedores de serviço, verificou-se uma melhoria significativa nos processos de beneficiamento de nãotecidos.
\end{abstract}

Palavras Chaves: reclamações de clientes, PDCA, ferramentas da qualidade, nãoconformidades, melhoria.

\begin{abstract}
This study searches to understand of the process involved in product elaboration and propose improvements to satisfy the customers. From the analysis of quality management system pointers, the main problems which need preventive/corrective actions were identified, among them, the high rate of complaints from customers who acquire benefited products. In this study, a stratification of primary causes complaints were carried out to, afterwards, identify ones which need to be attacked with priority. The quality managemental tools for improvement of benefited nonwoven process were applied. The execution action that attend some items of ISO 9001:2000 and PDCA cycle were used during the development of the work. Based on pointers as the claim of customers rate, non-conformity rate quality auditorship in the service suppliers, a significant improvement in benefited nonwoven process was verified.
\end{abstract}

Keywords: claim of customers, PDCA, quality tools, non-conformity, improvement. 


\section{INTRODUÇÃO}

O modelo clássico de relacionamento entre comprador e fornecedor baseava-se no julgamento de preços, prazos de entrega e qualidade do produto quando do recebimento do material encomendado, momento em que eram feitas inspeções qualitativas e quantitativas. Após essa fase, iniciava-se o processamento do pagamento e o processo era registrado na pasta do fornecedor para eventuais consultas futuras.

Esse tipo de procedimento se encontra em desuso, pois cada vez mais as empresas têm se preocupado em desenvolver parcerias, dentro de uma linha contemporânea em que o importante é estabelecer um relacionamento permanente entre cliente e fornecedor, envolvendo não somente compras eventuais ou programadas, como também o desenvolvimento de produtos.

Os fornecedores fazem parte de todo o processo produtivo de uma indústria, pois o "start" para a produção de determinado produto depende do fornecimento das matériasprimas. Além disso, o beneficiamento de produtos, conhecido como fornecimento de serviços, necessita ser padronizado para que o produto final tenha qualidade exigida pelos clientes e que esteja dentro dos parâmetros especificados. Portanto, os fornecedores passam a ser uma extensão da empresa, realizando um serviço específico e de grande importância para seus parceiros.

Dentro desse contexto, as empresas que possuem um Sistema de Gestão da Qualidade (SGQ) maduro tendem a auxiliar os seus fornecedores na busca da padronização de seus processos. Para trabalhar com o sistema de fornecedores confiáveis (modelo atual de fornecimentos na qual os produtos são recebidos com base nas inspeções de seus laudos técnicos), a empresa precisa estabelecer um vínculo de confiança com seu fornecedores. Quando se trata de atuais fornecedores, considera-se que o vínculo já esteja consolidado, bastando apenas ajustar o processo. Esse ajuste ou padronização se faz necessário para que a empresa que contrate o serviço de um fornecedor possa garantir ao seu cliente a qualidade de seus produtos e conformidade com as especificações.

Uma empresa do ramo de transformação de plástico, produtora de nãotecidos, buscando melhorar os seus processos de beneficiamento, mostrou-se interessada em aplicar o ciclo de PDCA de melhoria. Portanto, os processos que serão trabalhados são os de beneficiamento de nãotecidos adsorvedores de óleo, laminados e fibras cortadas, todos de 
polipropileno. Nesses processos, a empresa identificou um grande número de reclamações de clientes e gastos excessivos devido as não-conformidades dos produtos.

Com o objetivo de solucionar os problemas acima citado e ajustar os processos conforme os itens 7.4 (Aquisição) e 7.5.1 (controle de produção e fornecimento de serviços) da Norma ISO 9001:2000, foi realizado um trabalho de melhoria utilizando o ciclo de PDCA. Essa ferramenta visa melhorar e padronizar os processos de beneficiamento de modo a racionalizar e unificar as informações entre a empresa e os seus fornecedores de serviço.

Inicialmente identificaram-se os problemas através de uma relação de reclamações de clientes. Utilizando os conceitos de Pareto buscou-se identificar as "poucas causas vitais" que estariam gerando as reclamações. Com a mesma técnica, pode-se verificar quais reclamações geravam maiores custos de não-conformidades. Uma vez identificado o pequeno número de causas responsável pelo maior número de vezes que houve deterioração na qualidade do serviço, se fez a priorização dessas causas em uma matriz levando em conta a gravidade, urgência e tendência dos problemas (método GUT).

A etapa de análise teve a participação do grupo de desenvolvimento de produtos, e utilizando a ferramenta de brainstorming foram identificadas as causas mais prováveis da insatisfação dos clientes. Elas foram organizadas em um diagrama de afinidades formando grupos de assuntos afins. Esses grupos foram priorizados em uma matriz de priorização. Confirmando-se as causas mais prováveis, elaborou-se um plano de ação para o bloqueio das mesmas. Este plano é composto basicamente de ações que visam realizar a padronização dos processos e assegurar a qualidade dos produtos. Ele foi elaborado em tabelas do tipo $5 \mathrm{~W} 1 \mathrm{H}$ que os traduziram de forma clara e completa para o papel.

A etapa de ação constituiu-se na implementação dos planos de ação e contou com a participação do grupo de desenvolvimento de produtos e dos fornecedores de serviço uma vez que foi necessário treinamento e aplicação de procedimentos e instruções de trabalho. A fase de verificação foi realizada com base no número de reclamações de clientes monitoradas num espaço de tempo definido e nas auditorias dos processos de beneficiamento, objetivando verificar se o fornecedor está seguindo os procedimentos propostos pela empresa e se os processos estão organizados.

O trabalho foi concluído com a realização de um balanço dos resultados obtidos com a aplicação do PDCA de melhoria na padronização dos processos de beneficiamento de nãotecidos. 


\section{REVISÃO DE LITERATURA}

Antes de utilizar as ferramentas da qualidade, é necessária uma rápida revisão teórica. Essa revisão visa conceituar as ferramentas dentro dos conceitos clássicos da qualidade e orientar o leitor quanto a sua utilização.

\subsection{Ferramentas da Qualidade}

As ferramentas da qualidade são utilizadas para coletar, processar e dispor as informações necessárias ao giro do PDCA para manter e melhorar resultados. Segundo Kume (1993), as ferramentas da qualidade conferem objetividade e exatidão a observação, permitindo:

a) Dar maior importância aos fatos do que aos conceitos

b) Não expressar fatos em termos de intuição ou idéias

Folha de Verificação: uma folha de verificação é um formulário de coleta de dados, simplificando, onde o registro e análise dos dados são feito de forma rápida e simples. A folha de verificação pode ser usada para vários propósitos, mas sua característica desejável é tornar fácil a compilação de dados, de forma que eles possam ser utilizados e analisados rapidamente. Segundo Brassard (1992), uma folha de verificação é muito útil para responder perguntas do tipo “com que freqüência certos eventos acontecem?". Ela inicia o processo transformando "opiniões" em "fatos".

Gráfico Seqüencial: segundo a Associação Gaúcha da Qualidade, gráfico seqüencial é um gráfico de linha usado para acompanhar um dado quantitativo durante determinado período de tempo (cronologicamente). Essa ferramenta tem por objetivo detectar mudanças ao longo do tempo, fornecer o comportamento do dado quantitativo ao longo do tempo, ajudar a isolar num certo tempo uma possível mudança, monitorar o processo em relação a uma meta pré-estabelecida, etc.

Brainstorming: o brainstorming é uma técnica intencionalmente desinibidora, que ao ser empregada procura encorajar o pensamento criativo, para que as equipes possam gerar o maior número de idéias para uma determinada situação. O brainstorming tem como idéia principal suspender o pensamento crítico em favor do pensamento criativo, possibilitando a geração de idéias livres de preconceitos e paradigmas. 
Segundo Hegedus, uma possibilidade é executá-lo de forma não-estruturada, isto é, os participantes se manifestam em função da quantidade de idéias que lhe surgem, não havendo preferência de ordem dos participantes.

- Vantagens: há uma maior possibilidade de aumentar a criatividade e enriquecimento do processo.

- Desvantagem: muitas vezes ocorre o monopólio da palavra e do processo por uns poucos participantes.

Gráfico de Pareto: Esta análise tem como ponto de partida as causas levantadas no brainstorming ou outra fonte de coleta de dados, além de possuir processo de construção e elaboração semelhante ao do histograma. A diferença é que ao invés de avaliar a distribuição de freqüências do efeito principal, a análise $\mathrm{ABC}$ ou gráfico de Pareto, como é mais conhecido, permite identificar como se distribuem as causas que contribuem para este efeito principal. Segundo Brassard (1992), o diagrama de Pareto é uma forma especial do gráfico de barras verticais que permite diferenciar os poucos problemas vitais (pequeno número de causas responsável pelo maior número de vezes em que há deterioração na qualidade do serviço) dos poucos problemas triviais (grande número de causas responsável pelo número de vezes que o problema ocorre). A partir do topo da barra mais alta, traça-se uma linha para mostrar a medida cumulativa das categorias. Com isso visualizam-se quanto as primeiras duas ou três categorias respondem em relação ao valor total.

Diagrama de Afinidades: o diagrama de afinidades é a representação gráfica de grupos de dados afins, que são conjuntos de dados verbais que têm, entre si, alguma relação natural que os distinguem dos demais. Este diagrama é muito usado para reunir grupos de dados dispersos ou para organizar grupos confusos de dados. Quando as idéias formam um caos, quando o tema é muito grande, ou muito complexo, o diagrama de afinidades pode comportar-se como um "mapa geográfico".

O diagrama de afinidades tem se mostrado muito eficiente para:

- Direcionar a solução do problema;

- Organizar as informações necessárias à solução de problemas;

- Organizar as causas de um problema; 
Diagrama da Matriz de Priorização: o diagrama da matriz de priorização tem o objetivo de reduzir e ordenar, de forma racional, o número de itens a serem implementados. É uma ferramenta auxiliada pela matriz de afinidades, que tem a função de organizar os dados para posteriormente serem ordenados na matriz de priorização. O diagrama de matriz de priorização é uma matriz especialmente construída para ordenar uma lista de itens. É uma ferramenta para tomada de decisão, já que estabelece uma priorização, que pode ou não ser baseada em critérios com pesos definidos. Ele combina as técnicas de diagrama de árvore e do diagrama de matrizes e é representado pela matriz de priorização.

Matriz GUT: essa matriz é uma forma de se tratar problemas com o objetivo de priorizá-los. Ela leva em conta a gravidade, a urgência e a tendência de cada problema.

a) Gravidade: impacto do problema sobre coisas, pessoas, resultados, processos ou organizações e efeitos que surgirão em longo prazo, caso o problema não seja resolvido.

b) Urgência: relação com o tempo disponível ou necessário para resolver o problema.

c) Tendência: potencial de crescimento do problema, avaliação da tendência de crescimento, redução ou desaparecimento do problema.

Segundo Petrocchi (1998), a utilização dessa ferramenta deve ser feita pelo grupo de melhoria como de fossem "donos" do processo, de forma a estabelecer a melhor priorização dos problemas. Para essa análise são utilizados critérios de pontuação que vai de um a cinco, permitindo classificar em ordem decrescente de pontos os problemas a serem atacados na melhoria do processo.

O modo de construir uma matriz GUT é semelhante às etapas de construção da matriz de priorização. Elas diferenciam-se apenas pelos critérios utilizados para a priorização.

5WlH: é uma abordagem em forma de uma matriz de perguntas que orienta o grupo na obtenção de respostas e determinados problemas ou planos de ação. Segundo Hegedus (2004), 5W1H não seria necessariamente uma ferramenta da qualidade, mas uma sistemática para compreender melhor uma determinada situação, explorando seus diferentes aspectos. É um conceito derivado da abordagem Aristotélica de compreensão do mundo e definição de um método.

Os cinco W e um H são:

- What? - O que? 
- Who?-Quem?

- $\quad$ Where? - Onde

- When? - Quando

- Why? - Por que?

- How? - Como?

\subsection{Ciclo PDCA de melhoria}

Segundo Werkema (1995), o ciclo PDCA é um método gerencial de tomada de decisões para garantir o alcance das metas necessárias à sobrevivência de uma organização.

Para desenvolver o ciclo PDCA, quanto mais informações (fatos e dados, conhecimentos) forem agregadas ao método, maiores serão as chances de alcance da meta e maior será a necessidade da utilização de ferramentas da qualidade para coletar, processar estas informações durante o giro do PDCA.

O ciclo de PDCA de melhorias consiste em uma seqüência de procedimentos lógicos, baseados em fatos, dados, que objetiva localizar a causa fundamental de um problema para posteriormente eliminá-las. No giro deste ciclo, as ferramentas da qualidade atuarão como ferramentas para coleta, processamento e disposição das informações, permitindo a tomada de decisões confiáveis.

O ciclo PDCA estabelece, para alcance das metas de melhoria, oito etapas que devem ser seguidas para que o problema seja solucionado. A figura 1 mostra as oito etapas de modo simplificado. 


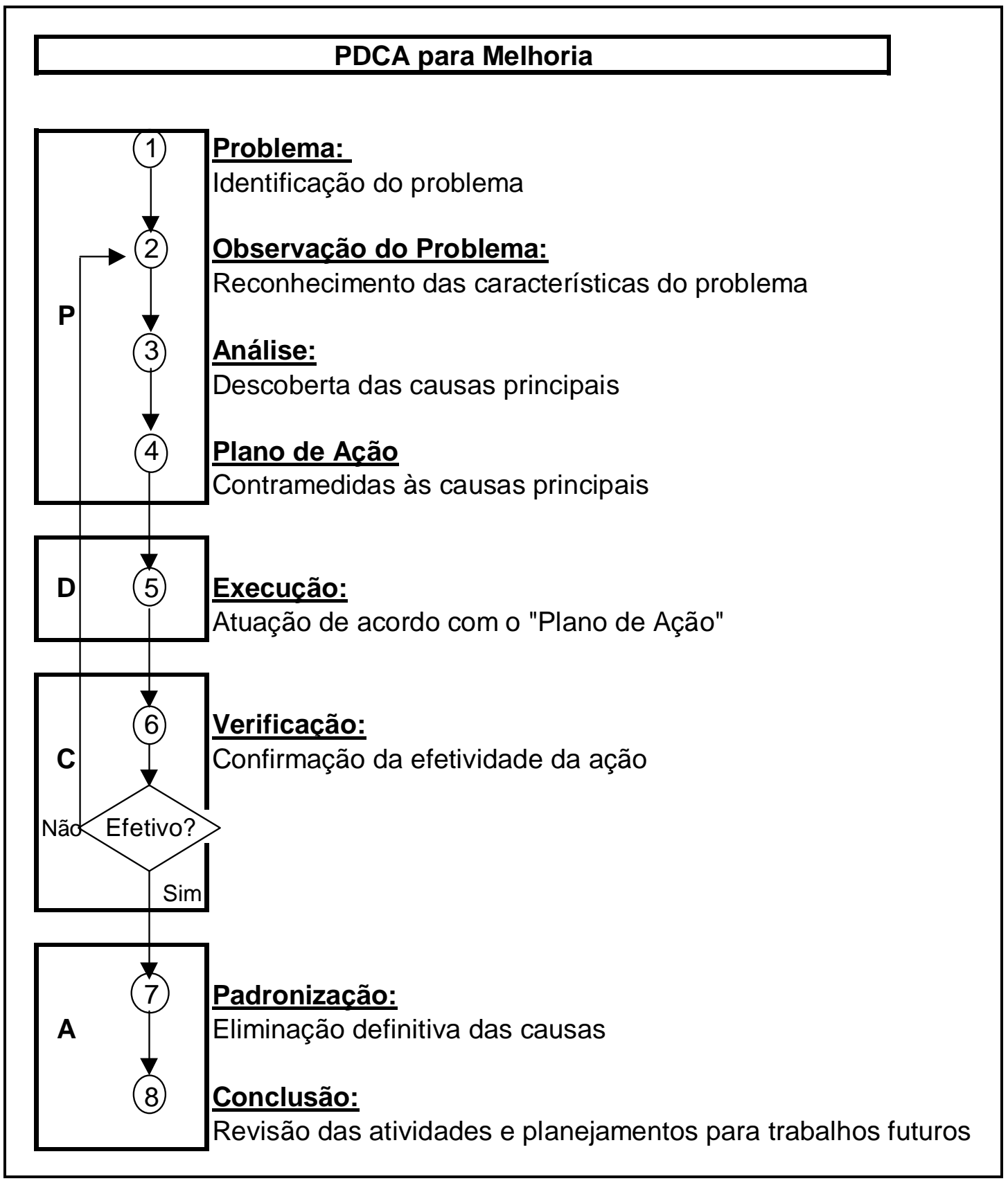

Figura 1: Ciclo PDCA utilizado para o alcance das metas de melhoria segundo Campos, V.F.1994 


\section{METODOLOGIA}

Uma indústria, produtora de nãotecidos, buscando realizar um trabalho de melhoria nos seus processos externos, mostrou interesse na aplicação do ciclo PDCA de melhorias e algumas ferramentas da qualidade de identificação e solução de problemas utilizados nesse método.

Desse modo realizou-se uma reunião entre os setores da qualidade e de desenvolvimento de produtos para comunicar que os produtos que são beneficiados foram alvos de reclamações de clientes em relação a sua qualidade. A existência de fornecedores de serviço permite com que haja processos produtivos que ultrapassam os domínios da empresa, conhecidos como processos externos. Esses processos, assim como os que estão sob o controle da empresa, necessitam ser padronizados justamente por serem uma extensão da organização precisando aderir aos padrões de qualidades exigidos de seus contratantes.

O trabalho é apresentado em duas etapas: a primeira mostra informações sobre o problema utilizando ferramentas básicas e avançadas da qualidade para a análise de processo, análise estatística e o giro do ciclo PDCA para melhoria. Na segunda, são aplicados os treinamentos necessários e o monitoramento dos resultados buscando identificar uma esperada melhoria.

O trabalho partiu do ponto em que foram identificadas as reclamações de clientes que adquirem produtos beneficiados. Através de um gráfico seqüencial (figura 2), podemos verificar ao longo do tempo o comportamento que teve o número de não-conformidades de beneficiamento. Em 2003 ocorreram 20 não-conformidades de beneficiamento, para 2004 a meta era diminuir em $25 \%$ esse número. Ao estipular uma meta máxima anual de 15 nãoconformidades, esperava-se não atingir tal número. Mas ao analisar o gráfico, pode-se perceber que no mês de maio de 2004 esse número já foi ultrapassado indicando haver problemas nesse processo. 


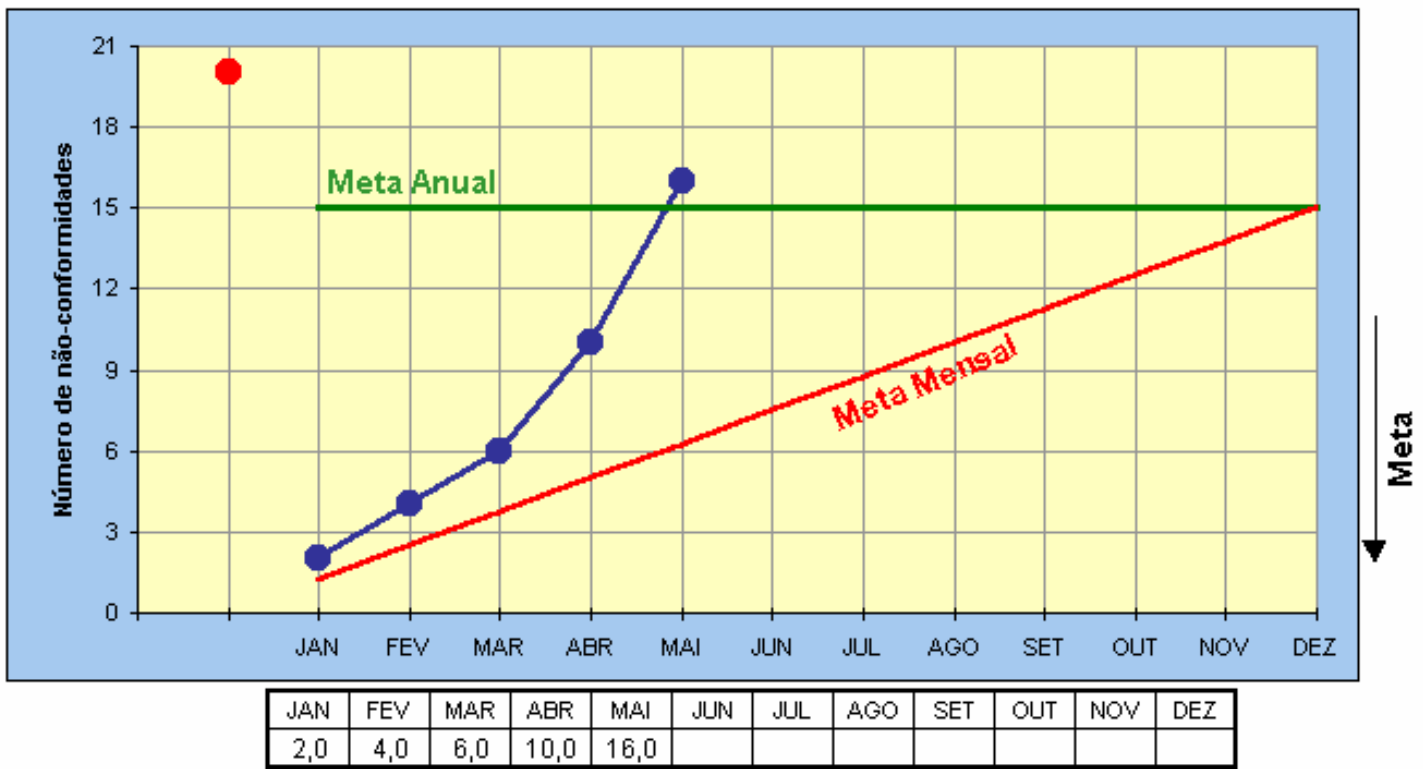

Figura 2: Gráfico seqüencial de controle de NC de beneficiamento

As não-conformidades foram tabuladas com base em reclamações de clientes, portanto, preparou-se uma tabela estratificando as reclamações e suas freqüências (número de ocorrências) para tentar identificar a origem do problema, como mostra a tabela 1.

Tabela 1: Lista de reclamações de clientes e quantidades das reclamações

\begin{tabular}{|l|c|c|}
\hline \multicolumn{1}{|c|}{ Reclamações } & Quantidade & $\begin{array}{c}\text { Área } \\
\text { Responsável }\end{array}$ \\
\hline \hline Produto fora de especificação & 6 & $\begin{array}{c}\text { Área } \\
\text { Téc/Qualidade }\end{array}$ \\
\hline Material recebido diferente do solicitado & 1 & $\begin{array}{c}\text { Fornecedor } \\
\text { Serviço }\end{array}$ \\
\hline Embalagem danificada & 2 & $\begin{array}{c}\text { Fornecedor } \\
\text { Serviço }\end{array}$ \\
\hline Confiabilidade do Produto ( m ateriais sem laudo) & 3 & $\begin{array}{c}\text { Area } \\
\text { Téc/Qualidade }\end{array}$ \\
\hline Material contaminado & 1 & Manufatura \\
\hline Quantidade errada de produtos por embalagens & 3 & $\begin{array}{c}\text { Fornecedor } \\
\text { Serviço }\end{array}$ \\
\hline
\end{tabular}

As reclamações referentes a produtos fora de especificação envolvem problemas de dimensões, resistência mecânica, delaminação e tipo de material. Para reclamações referentes à confiabilidade do produto, entende-se que o produto é pouco confiável devido a não existência de nenhum documento que comprove a sua análise e seu controle de qualidade. A contaminação de material que é mostrada na tabela acima refere-se a diferentes cores de pigmentos no material quando esse deveria de possuir uma única cor. 


\subsection{Elaboração dos Gráficos de Pareto}

Foram produzidos dois gráficos de Pareto, o primeiro irá mostrar quais são as nãoconformidades que geram maior número de reclamações, essas possivelmente serão trabalhadas já que representam grande parte das reclamações. O segundo irá mostrar quais não-conformidades geram maior custo para empresa. Com base no resultado dos gráficos, se chegará a conclusão de quais problemas realmente precisam ser atacados prioritariamente.

A tabela 2, apresentada abaixo, foi preparada para produzir um gráfico de Pareto, com o intuito de identificar os problemas que geram maior número de reclamações dos clientes.

Tabela 2: Planilha para construção do gráfico de Pareto (gráfico de quantidades)

\begin{tabular}{|c|c|c|c|c|c|}
\hline \multicolumn{6}{|c|}{ Distribuição de Freqüência } \\
\hline \multirow[b]{2}{*}{ Seq. } & Elaborador: Luis Gustavo & \multicolumn{2}{|c|}{ Data: 03/05/04 } & \multicolumn{2}{|c|}{ Processo: Beneficiamento } \\
\hline & Reclamações & Quantidade & $\begin{array}{l}\text { Quantidade } \\
\text { Acumulada } \\
\end{array}$ & $\begin{array}{c}\% \text { Total } \\
\text { Geral } \\
\end{array}$ & $\begin{array}{c}\% \\
\text { Acumulado }\end{array}$ \\
\hline 1 & Produto fora de especificação & 6 & 6 & 37,5 & 37,5 \\
\hline 2 & Confiabilidade dos produtos & 3 & 9 & 18,75 & 56,25 \\
\hline 3 & Quantidade errada de produtos por embalagens & 3 & 12 & 18,75 & 75 \\
\hline 4 & Embalagem danificada & 2 & 14 & 12,5 & 87,5 \\
\hline 5 & Material recebido diferente do solicitado & 1 & 15 & 6,25 & 93,75 \\
\hline 6 & Material contaminado & 1 & 16 & 6,25 & 100 \\
\hline & Total & 16 & - & 100 & - \\
\hline
\end{tabular}

\section{Gráfico de Pareto}

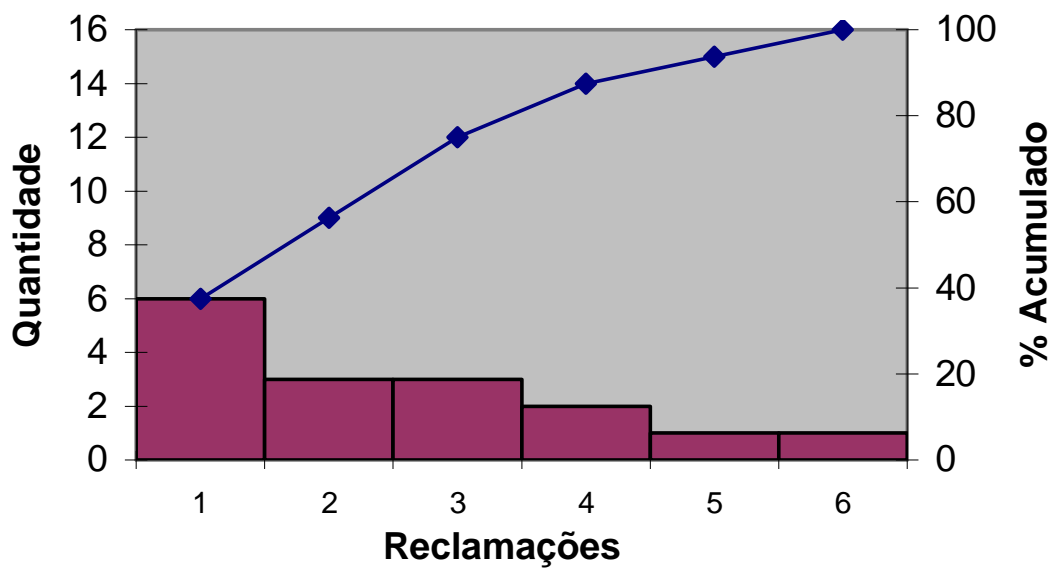

$\square \mathrm{N}^{\circ}$ de reclamações $\multimap \%$ Acumulado

Figura 3: Gráfico de Pareto de Quantidades 
Com base no gráfico de Pareto (figura 3), pode-se constatar que os problemas que geram maior número de reclamações são: produto fora de especificação, confiabilidade dos produtos, quantidades errada de produtos por embalagem. Para verificar se esses problemas são representativos e geram custos elevados de não-conformidade, foi elaborado um segundo gráfico de Pareto.

A tabela 3, apresentada abaixo, foi preparada para produzir um gráfico de Pareto, com o intuito de identificar os problemas que geram maior custo de não-conformidade.

Tabela 3: Planilha para construção do gráfico de Pareto (gráfico de custos)

\begin{tabular}{|c|c|c|c|c|}
\hline \multicolumn{5}{|c|}{ Distribuição de Frequiência } \\
\hline Elaborador: Luis Gustavo & Data: & Proce & so: Benefic & amento \\
\hline Reclamaçöes & Custo & $\begin{array}{c}\text { Custo } \\
\text { Acumulado }\end{array}$ & $\begin{array}{c}\% \text { Total } \\
\text { Geral }\end{array}$ & \begin{tabular}{|c|}
$\%$ \\
Acumulado \\
\end{tabular} \\
\hline Produto fora de especificaçẫo & $\mathrm{R} \$ 10.672,88$ & $\mathrm{R} \$ \quad 10.672,88$ & 74,4 & 74,4 \\
\hline Confiabilidade dos produtos & $\mathrm{R} 9 \quad 2.853,50$ & $\mathrm{R} \$ \quad 13.526,38$ & 19,9 & 94,2 \\
\hline Quantidade errada de produtos por embalagens & 620,96 & $\mathrm{R} \$ \quad 14.147,34$ & 4,3 & 98,6 \\
\hline Material recebido diferente do solicitado & 138,00 & $\mathrm{R} \$ \quad 14.285,34$ & 1,0 & 99,5 \\
\hline Material contaminado & 69,00 & $\mathrm{R} \$ \quad 14.354,34$ & 0,5 & 100,0 \\
\hline Embalagem danificada & $\mathrm{R} \$$ & $\mathrm{R} \$ \quad 14.354,34$ & 0,0 & 100,0 \\
\hline Total & 14354,34 & - & 100 & - \\
\hline
\end{tabular}

\section{Gráfico de Pareto}

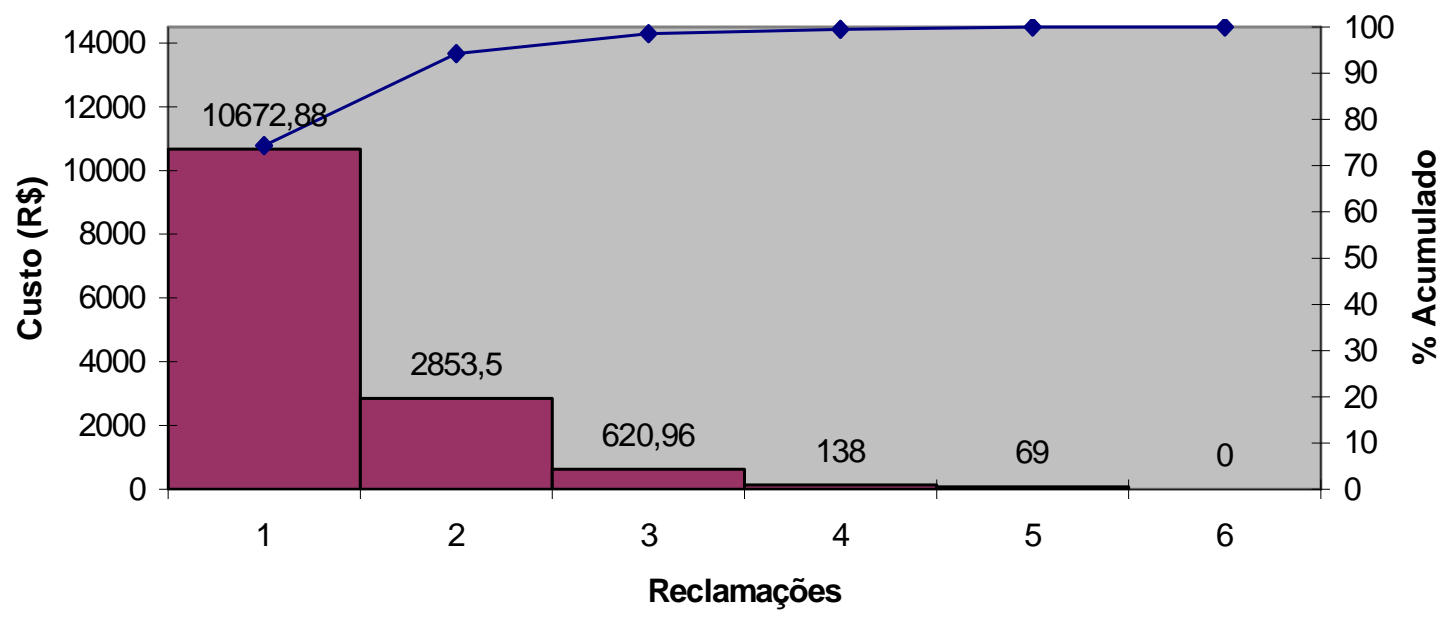

$\square$ Custo de não-conformidade $\multimap$ ๑ Acumulado

Figura 4: Gráfico de Pareto de custo de não-conformidade

Com base nesse gráfico (figura 4) pode-se constatar que os problemas que geram maior custo de não-conformidade são os mesmos que representam $75 \%$ das reclamações de 
clientes. Os custos de produtos fora de especificação são altos devido às devoluções desses produtos e o não aproveitamento deles. As não-conformidades ocasionadas devido a confiabilidade do produto, ou seja, produtos emitidos sem laudos de controle, geraram custos de não-conformidade não muito altos mas significativos. Esses produtos foram devolvidos para empresa. Os custos provenientes de quantidades erradas por embalagens foram gerados devido a reposição dos produtos aos clientes. As embalagens danificadas mesmo possuindo duas reclamações não geraram custo de não-conformidade, pois os clientes somente alertaram a empresa do problema sem devolver o material.

Ao analisar os dois gráficos, pode-se perceber que os problemas que necessitam ser trabalhados primeiramente são: os relacionados a produtos fora de especificação, confiabilidade do produto e embalagens com quantidade de material errada. Para saber qual a prioridade ao se solucionar esses problemas, utilizou-se da ferramenta matriz GUT que será apresentada a seguir.

\subsection{Elaboração da Matriz GUT}

Foi elaborada uma matriz GUT com o objetivo de priorizar os problemas levando em conta a gravidade, urgência e tendência de cada um. Para elaborar essa matriz são utilizados critérios de análise (apresentados na tabela 5) que permitem classificar em ordem decrescente de pontos os problemas a serem atacados na melhoria do processo. Essa análise foi realizada pelo grupo de desenvolvimento de produto da empresa, conhecedor dos processos, que em consenso chegou na ordem de priorização mostrada na tabela 4

Tabela 4: Matriz de GUT

\begin{tabular}{|l|c|c|c|c|c|c|}
\hline \multicolumn{9}{|c|}{ Matriz GUT } \\
\hline Elaborador: Luis Gustavo Setor: Qualidade & Data: $11 / 05 / 04$ & \multicolumn{3}{c|}{ Processo: Beneficiamento } \\
\hline \multicolumn{1}{|c|}{ Reclamações } & G & U & T & Total & Priorização \\
\hline \hline Produto fora de especificação & 5 & 5 & 4 & 14 & $1^{\circ}$ \\
\hline Confiabilidade dos produtos & 4 & 5 & 3 & 12 & $2^{0}$ \\
\hline Quantidade errada de produtos por embalagens & 3 & 3 & 3 & 9 & $3^{\circ}$ \\
\hline
\end{tabular}

Tabela 5: Critérios utilizados para elaboração da matriz GUT

\begin{tabular}{|c|l|}
\hline Pontos & \multicolumn{1}{c|}{ Critérios para Análise da Matriz GUT } \\
\hline \hline 5 & G (extremamente graves), U (ação imediata), T (tende a piorar de imediato) \\
\hline 4 & G (muito grave), U (com alguma urgência), T (vai piorar a curto prazo) \\
\hline 3 & G (grave), U (o mais cedo possível), T (vai piorar a médio prazo) \\
\hline 2 & G (pouco grave), U (pode esperar um pouco), T (vai piorar a longo prazo) \\
\hline 1 & G ( sem gravidade), U (não tem pressa), T (não vai piorar) \\
\hline
\end{tabular}


Os problemas que deverão ser trabalhados primeiro conforme a matriz acima são os de produtos fora da especificação e envio de material sem laudo técnico. O seguimento no trabalho será dado com a realização de uma sessão de brainstorming sobre os problemas priorizados.

\subsection{Sessão de Brainstorming 1}

Foi realizada com o grupo de desenvolvimento de produtos uma sessão de brainstorming procurando identificar quais os fatores que estariam levando a ocorrência desses problemas. Essa sessão foi do tipo brainstorming não estruturado onde os participantes se manifestaram em função da quantidade de idéias que lhe surgiam, não havendo preferência de ordem dos participantes. As idéias foram registradas em um quadro (tabela 6) onde ficou disponível para que todos os participantes pudessem ler. Os dados para a reunião são os seguintes:

Problema: Reclamações de clientes relacionado a problemas de produto fora de especificação e ausência de laudo técnico de produto acabado prejudicando a confiabilidade do produto final.

Objetivo: Identificar quais os fatores que estariam levando a ocorrência desses problemas.

Tabela 6: flip-chart do brainstorming 1

\begin{tabular}{|c|l|}
\hline Ordem & Descrição dos Possíveis Fatores \\
\hline 1 & Largura das tiras de desuniforme \\
\hline 2 & O processo de beneficiamento não é claro \\
\hline 3 & Limpeza do material (material com poeira) \\
\hline 4 & Peso por embalagens errada \\
\hline 5 & Dimensões dos tapetes adsorventes trocados \\
\hline 6 & Não existência de um fluxo dos processos \\
\hline 7 & Não existência de um documento guia \\
\hline 8 & Produto pouco confiável após beneficiamento \\
\hline 9 & Manuseio do material \\
\hline 10 & Embalagens danificadas (fechamento inadequado) \\
\hline 11 & Treinamento não claro \\
\hline
\end{tabular}




\begin{tabular}{|c|l|}
\hline 12 & Funcionário novo sem treinamento \\
\hline 13 & Tipo de embalagem inadequada \\
\hline 14 & Material adsorvente para barreiras trocado \\
\hline 15 & Comunicação falha entre fornecedor e empresa \\
\hline 16 & Confusão no embalamento das fibras da construção civil \\
\hline 17 & Inexistência de IT para embalamento das fibras construção civil \\
\hline 18 & Gramatura errada do nãotecido para produtos laminados \\
\hline 19 & Matéria-prima da Lâmina errada \\
\hline 20 & Não realização de análise após o beneficiamento \\
\hline 21 & Inexistência de indicadores de controle de qualidade \\
\hline 22 & Funcionários desmotivados \\
\hline 23 & Aparelhos de pesagem não calibrados \\
\hline 24 & Funcionários não conhecem procedimentos \\
\hline 25 & Material identificado errado na nota fiscal \\
\hline 26 & Especificação boca-boca \\
\hline 27 & Não envio das especificações de produto \\
\hline 28 & Material contaminado por insetos \\
\hline 29 & Etiquetas do material trocadas na produção \\
\hline 30 & Erro ao contar as quantidades de material por embalagens \\
\hline 31 & Caixas menores do que o volume especificado \\
\hline & \\
\hline 23 & \\
\hline 23 &
\end{tabular}

O brainstorming ou tempestade de idéias é uma ferramenta que visa coletar informações diversas que ajudam na solução de problemas, não obedecendo a uma ordem de assuntos. O objetivo foi de coletar idéias sem estabelecer a ordem na qual elas deveriam ser expostas. Com base nas informações apresentadas no brainstorming, foi utilizada uma ferramenta que permite organizar as idéias propostas, o diagrama de afinidades.

\subsection{Elaboração do Diagrama de afinidades}

Esse método teve o objetivo de organizar em blocos de assuntos afins, os possíveis fatores que estariam contribuindo para a insatisfação dos clientes. Em outras palavras, 
objetiva agrupar as possíveis causas do problema em blocos de mesmo assunto como mostra a tabela 7. 
Tabela 7: Diagrama de afinidades

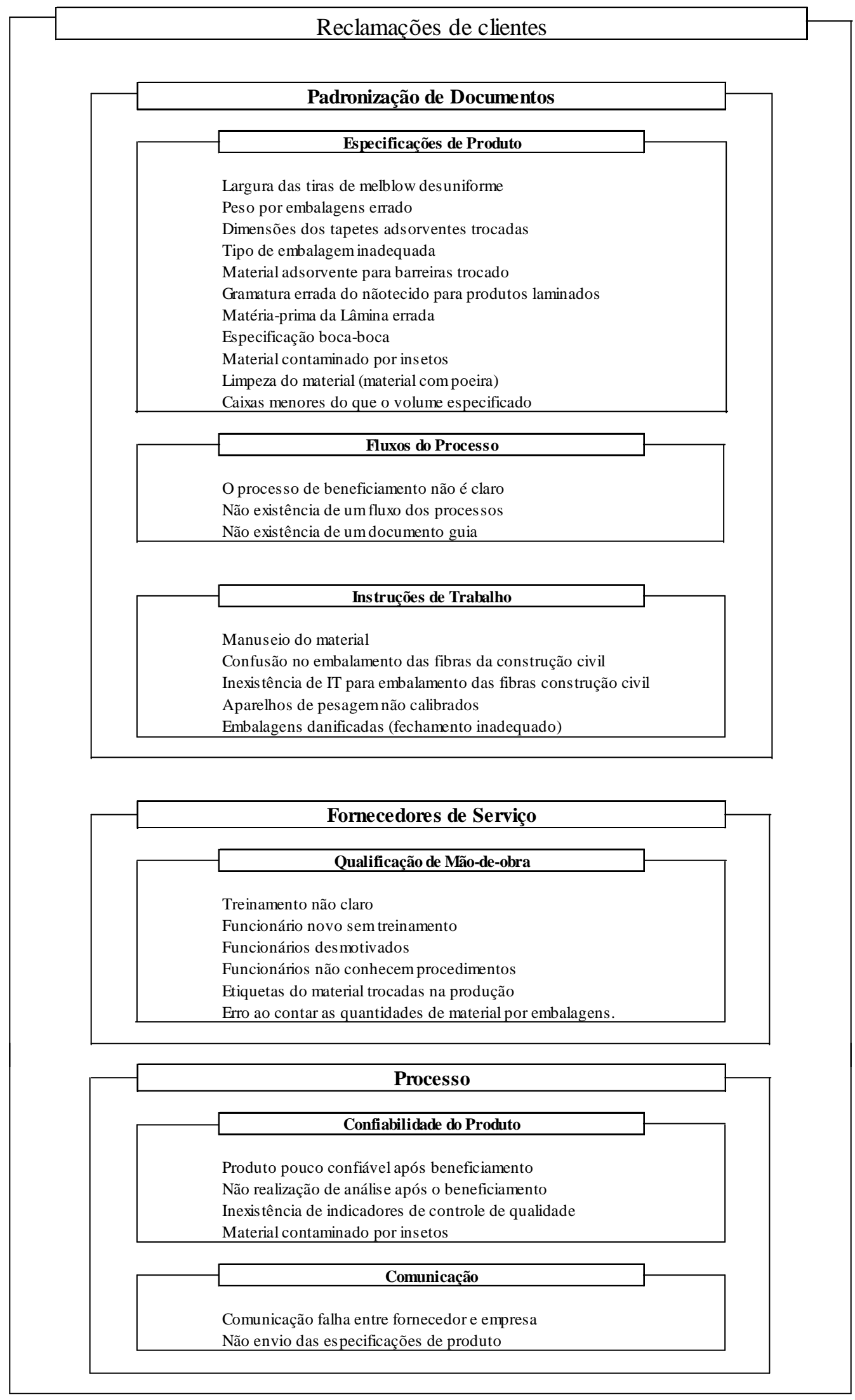


Essa técnica foi desenvolvida junto com o grupo de desenvolvimento de produto logo após encerrada a sessão de brainstorming. O diagrama de afinidades permitiu agrupar as idéias gerando blocos de temas afins, facilitando, assim, a utilização da ferramenta seguinte, o diagrama de priorização por consenso.

\subsection{Elaboração do Diagrama de Matriz de Priorização}

Até agora, as ferramentas permitiram que se organizasse uma lista de itens de um tema e que eles fossem relacionados e ordenados. Entretanto, com exceção da matriz GUT, nenhuma delas permitiu que se estabelecesse a ordenação de itens em função de critérios com pesos diferentes. Assim como o método GUT, a matriz de priorização reduz e ordena, de forma racional, o número de itens a serem implementados ou melhorados. A partir dessa fase do trabalho inicia-se a ordenar uma lista de assuntos para que seja tomada a decisão de ações para a resolução do problema e melhoria dos processos.

Com base nos grupos e subgrupos formados na matriz de afinidades, elaborou-se uma matriz de priorização de consenso. Essa técnica visa estabelecer a priorização nas soluções dos problemas com base em critérios e consenso do grupo de trabalho, ou seja, cada integrante do grupo votou com base no critério que achou pertinente em todos os itens relacionados na matriz. As tabelas 8 e 9 mostram, respectivamente, a matriz de priorização e critérios utilizados para a sua elaboração.

Tabela 8: Matriz de priorização

\begin{tabular}{|c|c|c|c|c|c|c|c|c|}
\hline & \multicolumn{8}{|c|}{ Matriz de Priorização } \\
\hline & Elaborador: Luis Gustavo & Seto & ial & & & ocesso:Ber & efician & iento \\
\hline \multirow[t]{2}{*}{ Grupo } & \multirow{2}{*}{$\begin{array}{c}\text { Problemas levantados no } \\
\text { brainstorming }\end{array}$} & \multicolumn{4}{|c|}{$\begin{array}{c}\text { Votação dos integrantes } \\
\text { do grupo de } \\
\text { trabalho }\end{array}$} & \multirow[t]{2}{*}{ Sub Total } & \multirow[t]{2}{*}{ Total } & \multirow{2}{*}{$\begin{array}{l}\text { Prior } \\
\text { dade }\end{array}$} \\
\hline & & 1 & 2 & 3 & 4 & & & \\
\hline \multirow{3}{*}{1} & Especificações Técnicas & 3 & 3 & 3 & 3 & 12 & \multirow{3}{*}{36} & \multirow{3}{*}{$1^{\circ}$} \\
\hline & Instruções de Trabalho & 3 & 3 & 3 & 3 & 12 & & \\
\hline & Fluxos do Processo & 3 & 3 & 3 & 3 & 12 & & \\
\hline \multirow{2}{*}{2} & Confiabilidade do produto & 3 & 2 & 3 & 3 & 11 & \multirow{2}{*}{15} & \multirow{2}{*}{$2^{\circ}$} \\
\hline & Comunicação & 0 & 1 & 2 & 1 & 4 & & \\
\hline 3 & Qualificação da Mão de obra & 1 & 0 & 1 & 1 & 3 & 3 & $3^{\circ}$ \\
\hline
\end{tabular}

Grupo 1: Padronização de documentos da

Grupo 2: Processo

Grupo 3: Fornecedores de 
Tabela 9: Critérios utilizados para elaboração da matriz de priorização

\begin{tabular}{|l|c|}
\hline \multicolumn{2}{|c|}{ Critérios para Análise da Matriz de Priorização } \\
\hline \hline 0 & Nenhuma Prioridade \\
\hline 1 & Razoável Prioridade \\
\hline 2 & Média Prioridade \\
\hline 3 & Grande Prioridade \\
\hline
\end{tabular}

Como pode-se perceber, a soma das notas obtidas em cada item estabelece o valor dos subgrupos, que quando somados, determinam um valor total que irá definir a priorização de cada grupo. Com base na matriz, o grupo que deve ser trabalhado por primeiro é o de padronização de documentos da qualidade, pois obteve nota total 36, a mais alta. No entanto, resolveu-se trabalhar, paralelamente, o assunto confiabilidade de produto, pois mesmo o seu grupo não atingindo uma nota que permitisse prioridade principal, o subgrupo desse item obteve um valor alto merecendo atenção.

\subsection{Sessão de Brainstorming 2}

Conhecendo-se agora, quais os itens que devem ser trabalhados com prioridade, realizou-se um segundo brainstorming com o grupo de desenvolvimento de produto tendo o objetivo de coletar idéias para solucionar esses problemas. Para explorar a possibilidade do grupo de correlacionar assuntos e tirar conclusões, ou então da mente encontrar soluções quando desligados do problema principal, realizou-se um brainstorming individualmente com cada integrante do grupo de trabalho. Desta forma, anotaram-se todas as idéias que surgiram referentes ou não ao problema em questão, fazendo-se posteriormente uma separação. As idéias mais significativas foram listadas na tabela 10 .

Objetivo: Coletar as idéias que poderiam solucionar os problemas relacionados à padronização dos documentos da qualidade e confiabilidade do processo.

Tabela 10: Flip-chart do brainstorming 2

\begin{tabular}{|c|l|}
\hline Ordem & \multicolumn{1}{|c|}{ Descrição dos Possíveis Fatores } \\
\hline 1 & Elaborar especificações técnicas de cada produto \\
\hline 2 & Elaborar procedimentos de todos os processos externos \\
\hline 3 & Exigir laudo dos fornecedores de serviço \\
\hline 4 & Especificar quais os itens controlados de cada produto \\
\hline 5 & Realizar auditoria nos fornecedores de serviço \\
\hline
\end{tabular}




\begin{tabular}{|c|l|}
\hline 6 & Elaborar instruções de trabalho para embalagens \\
\hline 7 & Garantir o conhecimento dos documentos pelo fornecedor \\
\hline 8 & Eliminar especificação boca-boca \\
\hline 9 & Enviar, a cada nova revisão, os documentos para o fornecedor \\
\hline 10 & Realizar a análise após o beneficiamento \\
\hline 11 & Garantir que os funcionários dos fornecedores foram treinados \\
\hline 12 & Emitir laudo junto com o produto e uma cópia para empresa \\
\hline
\end{tabular}

\subsection{Elaboração do Plano de Ação}

Analisando o flip-chart do segundo brainstorming, pode-se estabelecer ações que deveriam ser tomadas de modo a permitir o bloqueio das causas fundamentais. Para essa etapa foi utilizada uma matriz de perguntas que orienta o grupo na obtenção de respostas a determinados problemas ou plano de ação. O 5W1H não é necessariamente uma ferramenta da qualidade, mas sim uma sistemática para compreender determinada situação, explorando seus diferentes aspectos. Ela ajuda no cumprimento das ações, além de estabelecer prazos, responsáveis, o que e como fazer cada ação. Na tabela 11 é mostrado o plano de ação para a solução dos problemas levantados.

Tabela 11: Plano de ação 5W1H

\begin{tabular}{|c|c|c|c|c|c|}
\hline O que? & Quem? & Onde? & Quando? & Por que & Como? \\
\hline $\begin{array}{l}\text { Confiabilidade do } \\
\text { produto }\end{array}$ & Gustavo/Qualidade & $\begin{array}{l}\text { Fornecedores de } \\
\text { Serviços }\end{array}$ & $\begin{array}{c}1 \% / 06 / 2004 a \\
14 / 06 / 2004\end{array}$ & $\begin{array}{l}\text { Para comprovar ao } \\
\text { cliente a qualidade } \\
\text { dos produtos atráves } \\
\text { de seu controle }\end{array}$ & \begin{tabular}{|c|} 
Exigir laudos \\
técnicos, estabelece \\
indicadores de \\
qualidade dos \\
produtos \\
\end{tabular} \\
\hline $\begin{array}{c}\text { Elaborar } \\
\text { Especificações } \\
\text { Técnicas de cada } \\
\text { produto } \\
\end{array}$ & Gustavo/Qualidade & $\begin{array}{l}\text { Processo de } \\
\text { beneficiamento }\end{array}$ & $\begin{array}{c}14 / 06 / 2004 a \\
30 / 06 / 2004\end{array}$ & $\begin{array}{l}\text { Para padronizar as } \\
\text { informações }\end{array}$ & $\begin{array}{c}\text { Pesquisa com o grup } \\
\text { de desenvlvimento de } \\
\text { produto }\end{array}$ \\
\hline $\begin{array}{c}\text { Elaborar Instrução de } \\
\text { Trabalho para } \\
\text { Construção Civil }\end{array}$ & Gustavo/Qualidade & $\begin{array}{l}\text { Fornecedores de } \\
\text { Serviços }\end{array}$ & $\begin{array}{c}14 / 06 / 2004 a \\
30 / 06 / 2005\end{array}$ & $\begin{array}{c}\text { Para padronizar as } \\
\text { informações }\end{array}$ & $\begin{array}{c}\text { Acompanhar o } \\
\text { processo de } \\
\text { embalamento de } \\
\text { fibras da construção } \\
\text { civil } \\
\end{array}$ \\
\hline Fluxos dos Processo & Gustavo/Qualidade & $\begin{array}{l}\text { Fornecedores de } \\
\text { Serviços }\end{array}$ & $\begin{array}{c}15 / 07 / 2004 a \\
09 / 08 / 2004\end{array}$ & $\begin{array}{c}\text { Para manter } \\
\text { procedimento } \\
\text { documentado dos } \\
\text { processos }\end{array}$ & \begin{tabular}{|c|} 
Acompanhando cada \\
processo procurandd \\
identificar e anotar a \\
sua ordem de \\
acontecimento \\
\end{tabular} \\
\hline Treinamento & Gustavo/Qualidade & $\begin{array}{l}\text { Fornecedores de } \\
\text { Serviços }\end{array}$ & $\begin{array}{c}23 / 08 / 2004 a \\
10 / 09 / 2004\end{array}$ & $\begin{array}{c}\text { Assegurar o } \\
\text { conhecimento dos } \\
\text { documentos da } \\
\text { qualidade }\end{array}$ & $\begin{array}{c}\text { Visitas aos } \\
\text { fornecedores de } \\
\text { serviço e expor o } \\
\text { material }\end{array}$ \\
\hline $\begin{array}{l}\text { Acompanhamento } \\
\text { dos indicadores }\end{array}$ & Gustavo/Qualidade & $\begin{array}{c}\text { Setor comercial da } \\
\text { empresa }\end{array}$ & $13 / 09 / 04$ a $31 / 11 / 04$ & $\begin{array}{c}\text { Acompanhar a } \\
\text { evolução do process }\end{array}$ & \begin{tabular}{|c|} 
Através de \\
formulários de ações \\
corretivas e contatos \\
de clientes
\end{tabular} \\
\hline $\begin{array}{l}\text { Auditoria dos } \\
\text { fornecedores }\end{array}$ & Gustavo/Qualidade & $\begin{array}{c}\text { Fornecedores de } \\
\text { Serviços }\end{array}$ & $\begin{array}{c}01 / 12 / 2004 a \\
15 / 12 / 2004\end{array}$ & \begin{tabular}{|c|} 
Verificar a \\
conformidade dos \\
processos de \\
beneficiamento com \\
os documentos da \\
qualidade \\
\end{tabular} & $\begin{array}{c}\text { Visitas aos } \\
\text { fornecedałds de } \\
\text { serviço }\end{array}$ \\
\hline
\end{tabular}




\subsection{Executando o Plano de Ação}

As ações foram executadas conforme planejado no $5 \mathrm{~W} 1 \mathrm{H}$, respeitando todas as datas propostas. O desenvolvimento dos documentos da qualidade e demais ações executadas foram realizadas através do acompanhamento dos processos, reuniões com os setores envolvidos e entendimento das reais necessidades dos clientes.

Para assegurar aos clientes a qualidade dos produtos beneficiados através de seu controle, contatou-se os mesmos solicitando a eles os indicadores que eram significativos para os materiais comprados. As informações coletadas foram documentadas e passou-se a exigir do fornecedor de serviço que analisasse e emitisse um laudo técnico comprovando a qualidade do produto acabado.

De modo a padronizar as informações e eliminar o envio de requisitos de produto por e-mail ou telefone ao fornecedor, ação que muitas vezes geravam confusão e erros de produção, elaborou-se especificações técnicas para cada produto beneficiado. A pesquisa dos requisitos dos produtos foi solicitada ao grupo de desenvolvimento e aos clientes. Essas especificações devem ser conhecidas pelos fornecedores e eles devem receber e ser treinado nos novos documentos e a cada mudança de revisão. Acompanhou-se, também, o processo de embalamento de fibras e elaborou-se uma instrução de trabalho para esse processo. Esse documento orienta para as quantidades de pacotes que devem conter cada embalagem e o seu modo de enfardamento e fechamento.

Cada processo foi acompanhado e procurou-se identificar e analisar a suas ordens de acontecimento. O objetivo dessa ação foi desenhar os fluxos dos processos de beneficiamento, torná-lo conhecido por todos os envolvidos, estabelecer a ordem mais lógica dos acontecimentos e manter documentado como procedimento de processos externos.

Para cada implantação dos documentos desenvolvidos, para cada nova atividade surgida e para cada nova sistemática de trabalho, realizou-se um treinamento com as pessoas envolvidas. Segundo Chiavenato (1999), treinamento não é apenas fornecer informação para que aprendam novos conhecimentos ou habilidades, mas, além disso, é dar formação básica para que os colaboradores aprendam novas atitudes, soluções e idéias. Portanto, foi necessário treinar os funcionários de modo a torná-los capazes de realizar as funções e serviços solicitados com a melhor eficiência possível.

Para garantirmos que os processos de beneficiamento estão em conformidade com os documentos da qualidade, estabeleceu-se que haverá visitas trimestrais em cada fornecedor para avaliar o seu processo. Foi desenvolvido um formulário de inspeção que deverá orientar 
o auditor nos pontos mais significativos e que devem ser verificados. Esse formulário pode ser visualizado no anexo I.

Além da auditoria, outros dois indicadores foram acompanhados durante um espaço de tempo estabelecido pelo plano de ação, o número de não-conformidades de beneficiamento e o contato dos clientes (reclamações). Através do monitoramento desses indicadores podemos acompanhar a evolução do processo e verificar se o bloqueio das causas do problema foi efetivo.

\section{RESULTADOS}

Para avaliar a efetividade das ações tomadas e se as causas bloqueadas são realmente as responsáveis pelas não-conformidades detectadas no início do processo, monitorou-se os indicadores estabelecidos durante um espaço de tempo planejado. Primeiramente, definiu-se às reclamações de clientes como indicador devido essa ser a origem do problema. Monitorando as reclamações, pode-se avaliar se as necessidades dos clientes estavam sendo atendidas e se os problemas que estão acontecendo está relacionado diretamente com os que foram solucionados ou se são outros novos problemas que devem ser resolvidos.

Para trabalhar em conjunto com esse indicador, foi planejado que se realizassem auditorias trimestrais de modo a avaliar o fornecedor quanto a qualidade do serviço realizado. Com esses dois indicadores pode-se avaliar à eficácia do trabalho de padronização, pois com o monitoramento desses itens de controle foi possível evidenciar ao mesmo tempo se os clientes da empresa estão sendo atendidos conforme suas necessidades e se a empresa está sendo atendida pelo fornecedor conforme procedimentos estabelecidos.

Foi realizada uma sessão de auditoria em todos os fornecedores de serviço da empresa. Essa auditoria teve o objetivo de avaliar três pontos essenciais do fornecedor: a organização, a conformidade com os documentos estabelecidos e a busca de evidências de treinamento dos funcionários. Uma das evidências de que o fornecedor estaria em conformidade com os requisitos solicitados pela empresa contratante é uma auditoria com nota igual ou maior a 85 .

De acordo com os resultados das auditorias que foram realizadas com cada fornecedor de serviço, pode-se constatar que todos estão cumprindo os procedimentos, as especificações técnicas e consequentemente as necessidades dos clientes. Isso pode ser evidenciado porque todos os fornecedores de serviço tiveram notas superiores a 85, resultando numa média geral 92 e mostrando que estão qualificados. 
$\mathrm{Na}$ etapa de verificação, que ocorreu de setembro a novembro, a empresa detectou apenas duas reclamações de clientes, ambas referentes a quantidade errada de produtos por embalagem. Essas duas reclamações geraram duas não-conformidades, conforme mostra o gráfico abaixo (figura 5). Pode ser observado, também, que nos últimos cinco meses a contar de junho apenas três não-conformidades foram detectadas, já nos primeiros cinco meses do ano houve 16. Pode-se constatar então que houve uma redução de $80 \%$ no número de reclamações de clientes e consequentemente no número de não-conformidades. A redução do número de reclamações começou em julho porque tomou-se medidas de contenção para que garantíssemos que o problema não viesse a acontecer novamente. Um outro dado que não foi utilizado como indicador mas pode fornecer informações de melhorias e ser usado para efeito comparativo, é o custo de não-conformidades. Nos primeiros cinco meses do ano, foi registrado um custo de não-conformidade de $\mathrm{R} \$ 14354,34$, já nos últimos meses gerou-se um custo para a empresa de $\mathrm{R} \$ 930,00$. Com base nessas informações, pode-se detectar uma redução considerável em relação a custos de não-conformidades, cerca de 93\%. O gráfico abaixo apresenta uma redução significativa no número de não-conformidades, mostrando

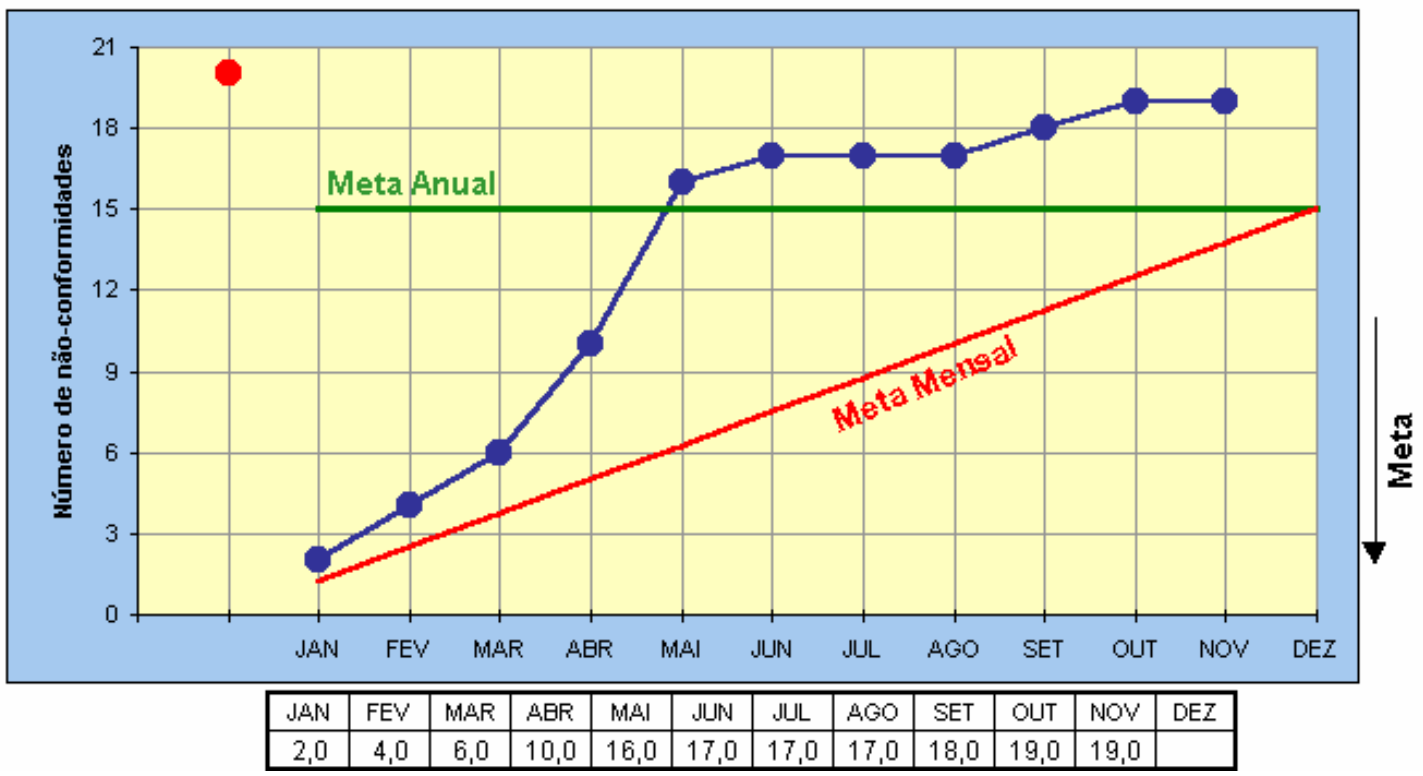

melhorias após a padronização dos processos.

Figura 5: Gráfico seqüencial de controle de não-conformidades de beneficiamento 


\section{CONCLUSÃO}

Após analisar os indicadores da qualidade pode-se fazer uma análise comparativa entre o processo antes de ser padronizado e após a sua padronização. Antes, apresentava altos índices de não-conformidades e um número elevado de reclamações de clientes insatisfeitos com os produtos recebidos, ou seja, um processo que não continha método de trabalho e que não se estabelecia normas para o serviço. Além disso, o processo de aquisição era precário, pois a organização não estabelecia claramente os requisitos especificados de aquisição, aprovação de produto, documentos que deveriam descrever as características produto e não avaliava o seu fornecedor de serviço regularmente.

Atualmente, pode-se perceber uma redução significativa do número de nãoconformidades e reclamações de clientes. $\mathrm{O}$ atual processo contém um procedimento que descreve sobre os treinamentos necessários para realizar o serviço, as verificações periódicas do fornecedor, a necessidade do fornecimento de laudos técnicos de produto acabado, os itens que devem ser analisado de cada produto e o fluxograma de cada processo. Esse documento faz referências a instruções de trabalho, que visam orientar o funcionário para execução correta de um serviço, e a especificações técnicas de produto, que descrevem todos os requisitos do produto a ser produzido.

Foi elaborado, também, um guia de auditorias de fornecedores de serviço. Ele visa controlar os processos externos e avaliar o fornecedor com base na sua capacidade em fornecer produtos de acordo com os requisitos estabelecidos. O guia é preenchido com base em critérios que visam quantificar a auditoria para verificar se os processos estão satisfatórios e se os fornecedores estão aptos a atender com êxito as necessidades dos clientes.

De modo geral, pode-se constatar uma real melhoria na execução dos processos de beneficiamento de nãotecidos. Alcançou-se um dos principais objetivos desse trabalho, reduzir o número de não-conformidades e reclamações de clientes. Além disso, as ações tomadas foram direcionadas também para atender aos itens 7.4 e 7.5.1 da norma ISO 9001:2000. Ambos os itens falam sobre o processo de aquisição e controle de produção e fornecimento de serviço que foram trabalhados junto com o fornecedor e incluídos nos procedimentos elaborados.

Para a melhoria do processo, se fez necessário padronizá-lo de modo a estabelecer claramente os requisitos e controles necessários. Para isso, se fez uso da ferramenta de PDCA para melhoria, que se mostrou eficiente por modificar as rotinas de trabalho e estabelecer novos padrões para serem seguidos. 


\section{REFERÊNCIAS BIBLIOGRÁFICAS}

Apostila “Gerenciamento da Qualidade Total”. Associação Gaúcha para a Qualidade (AGQ) BRASSARD, Michael. Ferramentas para uma melhoria Contínua. Ed. Qualitymark, 1992

CAMPOS, Vicente Falconi. TQC - Gerenciamento da Rotina do dia-a-dia, Minas Gerais, Fundação Christiano Ottoni, 1994

CHIAVENATO, Idalberto. Gestão de Pessoas: o novo papel dos recursos humanos nas organizações. Ed.Campus. Rio de Janeiro, 1999

HEGEDUS, Clovis E. Gerenciamento da Qualidade Total, Escola de Administração de Mauá, 2004

HEGEDUS, Clovis E. A qualidade total para a empresa brasileira. Seminário da Qualidade, CREA/RS, Porto Alegre, 1989.

KUME, Hitoshi; 1993, Métodos Estatísticos para a Melhoria da Qualidade, São Paulo, Editora Gente

Manual de Não-Tecidos: Classificação, Identificação e Aplicação. ABINT/ABNT. $2^{\circ}$ Edição, 2002

NBR ISO 9001. Sistemas de Gestão da Qualidade - Requisitos. Rio de Janeiro, dezembro de 2000 .

PETROCCHI, Mario. Turismo: Planejamento e Gestão. São Paulo. Ed. Futura, 1998

WERKEMA, Maria Cristina. Ferramentas Estatísticas Básicas para o Gerenciamento de Processos. Belo Horizonte. Editora Fundação Cristiano Ottoni, 1995 


\section{Anexo 1: GUIA PARA AUDITORA DOS PROCESSOS DE BENEFICIAMENTO}

\begin{tabular}{|l|l|}
\hline Processo auditado: & Auditor: \\
\hline Procedimentos_ & Data da Auditoria: \\
\hline
\end{tabular}

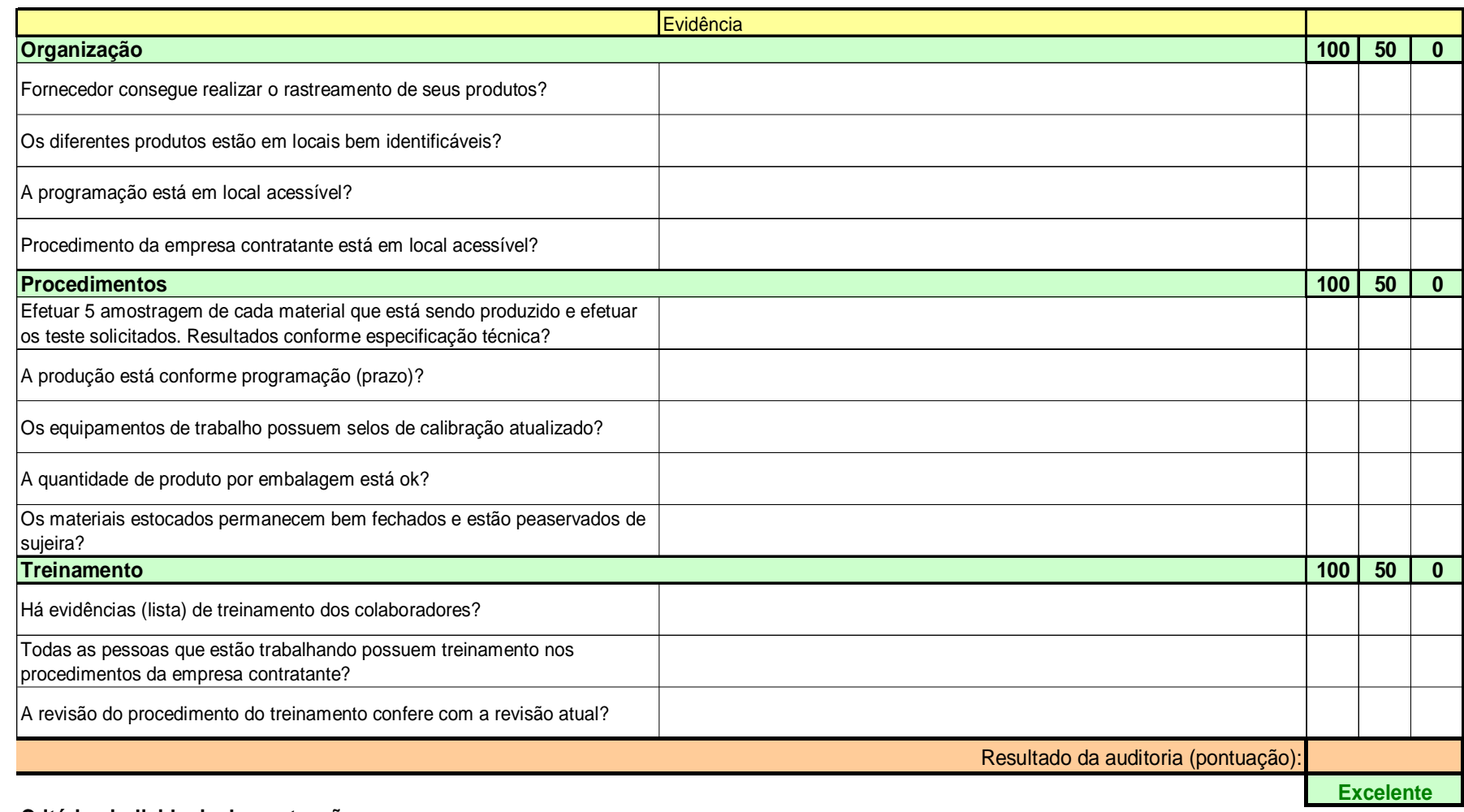

Critérios individuais de pontuação:

100\% Excelente - Ponto forte da empresa; o sistema está perfeito

$50 \%$ Insatisfatório - Ponto fraco; o sistema é falho; não está operante; há várias não-conformidades ou uma não-conformidade grave $0 \%$ Ruim - O item não cumpre o requisito solicitado

Artigo recebido em 22/09/2005 e aceito para publicação em 07/08/2006 